\title{
Revisiting Folded Forms with Digital Fabrication
}

\author{
Anna Szabo ${ }^{1}$,Ena Lloret-Fritschi ${ }^{2}$, Lex Reiter ${ }^{3}$, Fabio Gramazio ${ }^{4}$, \\ Matthias Kohler ${ }^{5}$, Robert J. Flatt ${ }^{6}$ \\ 1,4,5 Gramazio Kohler Research, ETH Zurich ${ }^{2}$ Gramazio Kohler Research, Institute \\ for Building Materials, ETH Zurich ${ }^{3,6}$ Institute for Building Materials, ETH Zurich \\ 1,2,3,4,5,6 \{szaboan|enal|lreiter|fabiog|makohler|flattr\}@ethz.ch
}

\begin{abstract}
This paper discusses the potential of emerging digital fabrication techniques to produce material-efficient thin folded concrete structures. Although in the 50s and 60 s folded structures provided a common optimal solution for spanning large distances without additional vertical supports, today, the number of these projects decreased significantly due to their complicated formworks and labour-intensive realization. Digital fabrication methods for concrete hold the promise to efficiently produce intricate folded mass-customized shapes with enhanced load-bearing capacity. This paper focuses on a robotic slip-forming process, Smart Dynamic Casting (SDC), to produce various thin-walled folded concrete elements with the same formwork providing smooth surface finish and gradual variations along the height. An empirical research methodology was applied to evaluate the fabrication feasibility of digitally designed thin folded geometries with one-to-one scale prototypes. Despite the discovered design limitations due to fabrication and material constraints, the exploration led to a new promising research direction, termed 'Digital Casting'.
\end{abstract}

Keywords: folded structures, digital concrete, Smart Dynamic Casting, set on demand, Digital Casting

\section{INTRODUCTION AND STATE OF THE ART}

Folded structures emerged in the early twentieth century as an optimal, material-efficient solution for spanning large distances with reinforced concrete (Engel and Rapson, 2007). They are threedimensional, spatial structures where the increased stiffness of the folded form enhances load-bearing capabilities (Lynn, 2004). Thus, folding functioned as a tectonic driver for architectural forms (Charleson, 2005).

The first folded structures were designed by architect-engineers such as Pier Luigi Nervi, Eduardo
\end{abstract}

Torroja or Hilario Candela, whose extensive knowledge of structural planning and building technology allowed for realizing intricate folded geometries (Clifford, 2011; Forty, 2012). Although these structures offered structural effectiveness and economical material usage, their construction was costly, wasteful and labour intensive due to the complex and extensive formwork structures needed for their realization (Szabo et al., 2018).

In the 1930s, the rationalization of the construction process led to radically simplifying the design of thin folded structures with planar geometries (Engel 
and Rapson, 2007). In the 50s and 60s, these folded plate structures became increasingly popular across Europe, North America and Asia (Garcia, 2006) as a sensible roofing solution for buildings with industrial, sport, educational or cultural functions. However, the economics of fabrication has propagated repetitive geometries due to the reuse of the same formwork, thus significantly restricting the design space within a specific project. Today, only a few remarkable examples of folded structures can be found both in research and in architectural practice. These projects go beyond the traditional folded plate typology by the use of advanced material compositions, special formworks or novel processing methods.

The first contemporary example, the Namics Headquarters in St. Gallen, Switzerland (Figure 1, Left) features a folded roof along the width of the building $(12.87 \mathrm{~m})$, to allow for an open space completely free from any vertical support. For this project, the flow behaviour of concrete was modified to enable casting on site a folded slab of varying thickness on a simple planar formwork without the need of counter-formwork (Pedrazzini, Pedrazzini and Guidotti, 2017).

Another example is the Mülimatt Sport Center in Brügg, Switzerland (Figure 1, Right) where the prefabricated folded concrete structure spans $55 \mathrm{~m}$ distance to fulfil the spatial requirement for the sports hall. The building was realized with large, expensive formworks integrating special features such as hydraulic opening mechanism, ventilation for entrapped air and post-tensioned cable positioning aids (Bruno et al., 2016). Both projects showcased challenges that motivated academic institutions in the last decades to initiate research on innovative fabrication methods that could efficiently produce complex, structurally informed folded elements.

The most advanced research projects addressing the efficient production of folded forms have been conducted in the Department for Structural Design at RWTH Aachen, Germany with textile reinforced concrete.

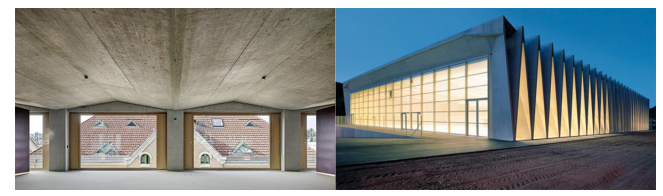

The first project, Concrete Fold, applies a manual manufacturing process to produce non-structural undulated façade elements (Pidun, 2016). The second project, Oricrete, also investigates prefabrication of folded plate structures at a horizontal plane and finalizes them on site with the support of a temporary scaffolding (Chudoba et al., 2014). A recent direction of the Oricrete project explores the fold-in fresh technology, where the freshly cast concrete plate is deformed before the curing of the matrix by changing the geometry of the formwork underneath from flat to spatially folded as illustrated in the right of Figure 2 (Hegger et al., 2017) These research projects hold potential to eliminate the need for elaborate, spatial formworks for folded plate constructions, their structural potential is limited by the textile reinforcement and they all include steps requiring extensive human labour.

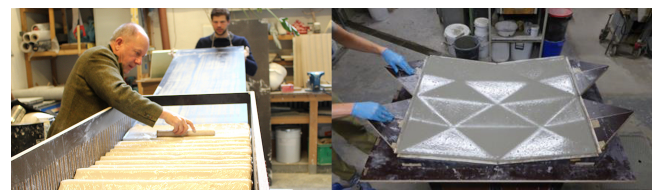

In the last decade, digital fabrication with concrete has revolutionised the way structures can be produced by controlling the setting of concrete on demand (Wangler et al., 2016). Although the concept of increasing the open time of concrete with a retarder and accelerating its setting was introduced already in 2012 for Concrete Printing at Loughborough University, UK (Le et al., 2012), it was first applied successfully during the digital fabrication process at another research, robotic slip-forming, Smart Dynamic Casting (SDC) at ETH Zürich, Switzerland (Lloret Fritschi, 2016). The set on demand system developed at ETH provided a breeding ground for emerging digital concrete technologies such as KnitCrete (Popescu et
Figure 1

Left: Namics

Headquarters, image reproduced from (Pedrazzini, 2017) Right: Mülimatt Sports Centre, image reproduced from (Bruno et al., 2016)

Figure 2

Left: Concrete Fold, image reproduced from (Pidun, 2016), Right: Oricrete fold-in fresh, image reproduced from (Hegger et al., 2017) 
Figure 3

The fabrication setup of SDC for thin folded geometries: A) ABB IRB 4600 6-axis robotic arm B) rigid folded formwork as end effector $\mathrm{C}$ ) concrete pump D) mixing reactor and the attached accelerator pump E) digital control al., 2018), 3D Concrete Extrusion (Das et al., 2019) and Digital Casting (Wangler, 2018; Szabo, Reiter, Lloretfritschi, et al., 2019).

This paper introduces the empirical methodology to produce thin folded structures with Smart Dynamic Casting. Due to the narrowness of the design space of this method, which is subject to many process constraints, the paper in its outlook also presents how a minor modification to the experimental setup can lead to a new process called Digital Casting which offers larger geometrical freedom for the digital fabrication of thin folded concrete structures.

\section{ROBOTIC SLIP-FORMING THIN FOLDED STRUCTURES \\ Physical setup}

Smart Dynamic Casting (SDC) is a digital fabrication process for robotically slip-casting concrete with formworks that define the shape from the sides and are open on top and bottom. It was chosen for the fabrication of thin folded structures due to its potential to induce gradual geometric variation along the length of the produced elements while providing smooth surface finish and the means to introduce reinforcement.
The experimental setup of SDC for thin folded structures consists of five components illustrated in Figure 3 starting with the 6-axis robotic arm (A) onto which a formwork is attached as an end effector (B). The formwork has L-shape and $2.5 \mathrm{~cm}^{*} 50 \mathrm{~cm} * 30 \mathrm{~cm}$ inner dimensions. It consists of an acrylic frame covered with a thin interchangeable PVC sheet at the inside to assure smooth surface. The two sides of the formwork are fixed at a 90-degree fold angle.

In slip-casting, concrete needs to support its own weight and the weight of the concrete above. For this reason, as fabrication occurs, it needs to build up strength, something that can be achieved by setting on demand.

First a big batch of slowly hardening concrete is prepared. At the start of the production, this retarded material is slowly pumped (C) into a customized mixing reactor (D) where specific dosages of chemical admixtures are added with a peristaltic pump to increase the rate of reactions and make the concrete set on demand (Lloret et al., 2015). Then, after being properly intermixed, the accelerated concrete exits the mixing reactor at its top and flows into the continuously moving formwork with the guidance of channels. Both the material dosing and the robotic slipping trajectory are digitally controlled to target a syn-

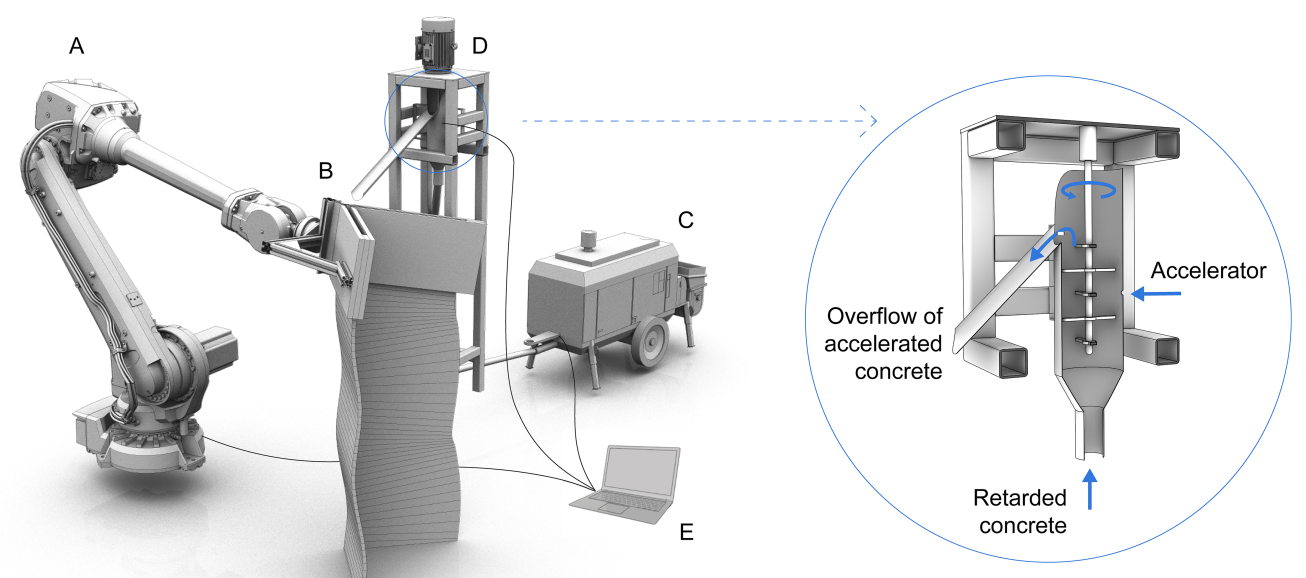


chronized process (E). The customized digital control methods of the different aspects of slipcasting will be described in the next section.

\section{Digital control for slip-casting}

The thin folded target geometries are designed with a digital design and fabrication tool developed in the framework of a student project (Wu and Giacomarra 2017). The tool uses the McNeels Rhinoceros environment with a custom-made Grasshopper plug-in (Figure 4). The digital tool enables to visualise the slipping process and the designed geometry based on the chosen formwork configuration, fold angle and fold curve. From the design of the folded element, the digital tool generates input for the fabrication that is sent to the robot through a communication platform that translates the data to a series of individual messages sent to the robot containing a single frame for the robotic slipping trajectory and the slipping speed.

Furthermore, the tool enables to integrate the fabrication constraints to the design at an early phase based on empirical findings for the possible degree of shaping (horizontal deviations from the vertical slipping direction as a reference). Later, the pre-set fabrication constraints can be updated with iterative fabrication studies producing one-to-one scale prototypes. Thus, the tool can predict increasingly better the locations where failures are expected to happen.
The composition, thus setting time of concrete is controlled by using a customized digital tool developed for a previous project phase (Scotto et al., 2018) at a reduced functionality to only regulate the pumping speed of the retarded concrete and the accelerator. Theoretically, the setting time is in direct relation with the slipping speed, however, in practice due to imperfections at filling it is beneficial to decouple the control over the material and the robotic motion (Scotto et al., 2018). Thus, the robotic slipping speed is adjustable either from the flex pendant or from $A B B$ RobotStudio during the experiments independently from the concrete processing.

\section{Process window}

The fabricated shape evolves from the interplay of the formwork geometry, the robotic formwork motion based on the output of the design tool and the control over the flow and hardening of concrete. However, shaping concrete is a delicate process that can easily fail with either too soft material flowing out of the formwork or too hard material getting stuck in the formwork due to friction and causing cracks (Lloret Fritschi, 2016).

The process window describes the specific conditions when slip-forming is possible (Szabo et al., 2018). Within the process window, the weight of the concrete inside the formwork provides a larger driving force than the friction occurring along the

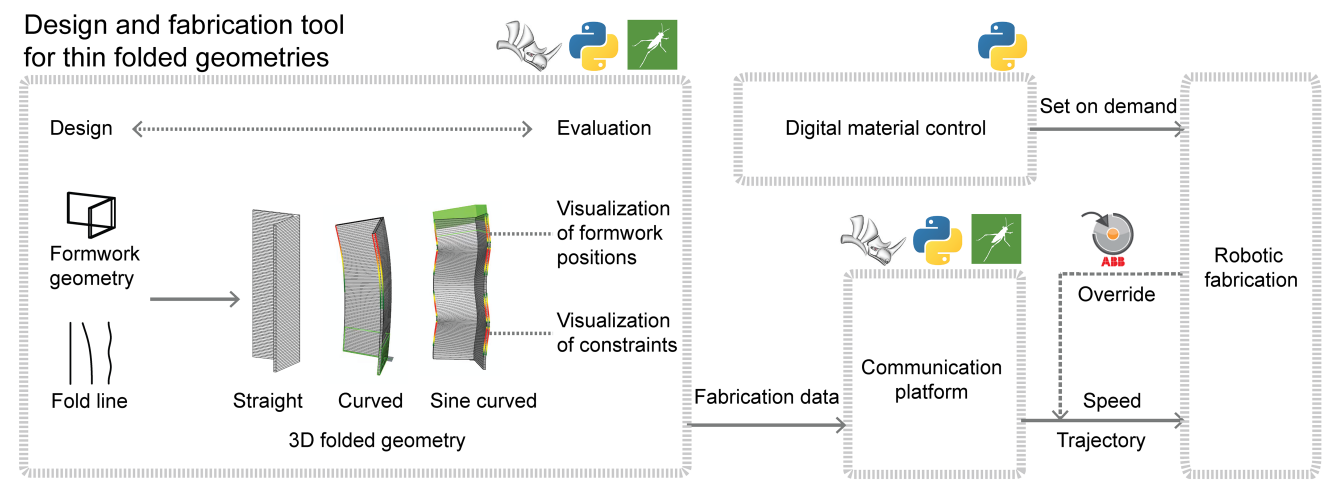

Figure 4 Digital control in the fabrication process 
Figure 5

Comparison of the strength evolution characteristics with fast and slow setting material. Initially, a faster setting material was used, then adjusted to a slower composition
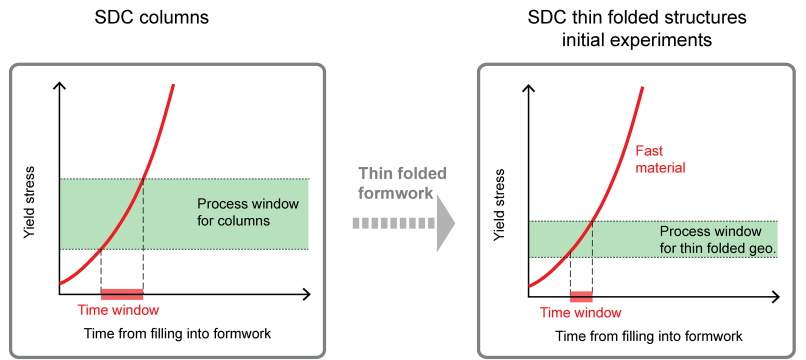

SDC thin folded structures second experimental phase

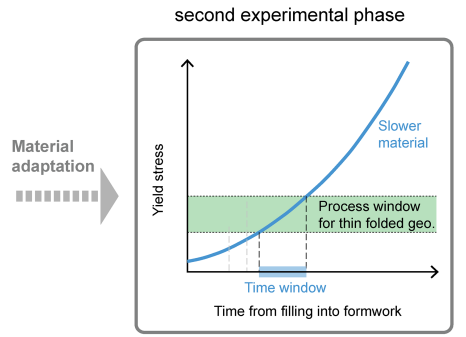

formwork walls obstructing slip-out. Thus, the process window depends on the ratio of the formwork volume and formwork surface and requires enough cohesion in the material for slipping (Szabo, Reiter, Lloret-Fritschi, et al., 2019). This cohesion can be described as a specific restricted range of a material property called yield stress that we can measure with different techniques such as slow or fast penetration tests already discussed in various publications (Mettler et al., 2016; Reiter et al., 2019). As described in Figure 5, the process window can also be described with the time interval during which the process window condition for yield stress is met.

Beyond the process window, there are further requirements for the material leaving through the bottom of the formwork. The faster it hardens the better it can resist buckling during production, and more inclinations, curvature for the slipping trajectory, higher shaping degree can be achieved, resulting in folded prototypes with intricate geometries.

\section{PROTOTYPES AND DISCUSSION Initial experiments}

The first thin folded concrete prototypes were produced by applying the original extensively published SDC process for columns with as little modification as possible to these new geometries. Only one component of the physical setup, the formwork, was exchanged to a thin folded design, while the material composition, the slipping and pumping speed remained consistent to previous SDC experiments.
However, this change already had a significant effect on the outcome of the SDC process leading to various failures such as fracturing, complete tear off at low height and uneven surfaces.

In order to investigate the cause of the unexpected failures, the slip-forming process was analysed and described with a process window model based on the physics of slip-forming and the influence of formwork geometry on it. It can be observed in Figure 5 that the process window is becoming significantly narrower for thin folded structures than for columns when using an identical material composition. This decrease is due to the increased surface area of the thin folded formwork where the friction hinders slipping (Szabo et al., 2018). Thus, the process model explains the increased difficulties experienced during the production of the first thin folded prototypes.

As a consequence (see the third diagram of Figure 5), the material composition was adjusted to achieve slower strength evolution, thus despite the narrow process window, similarly long time is available for slipping as seen for columns. Details of the material composition and the experimental setup can be found in a previous publication (Szabo et al., 2018). The material adjustments allowed for more robust slipping and marked the start of the second experimental phase where the exploration of possible thin folded geometries began. 


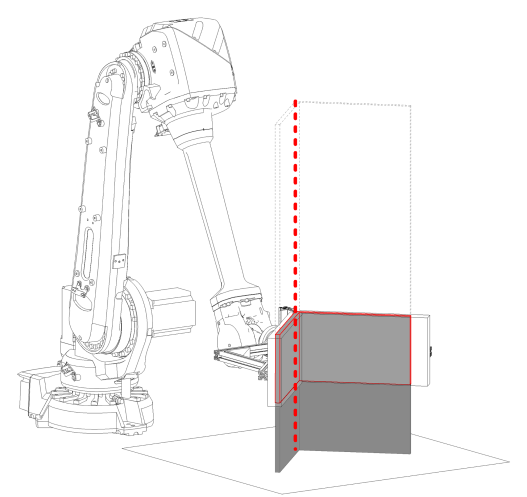

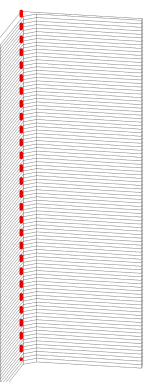

A

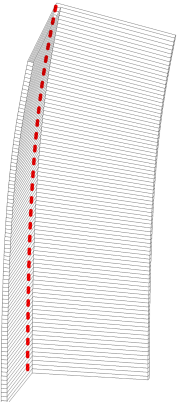

B

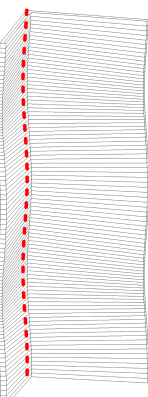

C

\section{Second experimental phase}

The empirical investigation of possible thin folded geometries took place along three strands. These strands can be distinguished with their straight, Bezier curve and sine curve trajectories (Figure 6) resulting in prototypes with various geometries produced with the same formwork (Figure 12).

Straight slipping. Firstly, straight vertical slipping was tested (see Figure 6) to verify the adapted material composition.

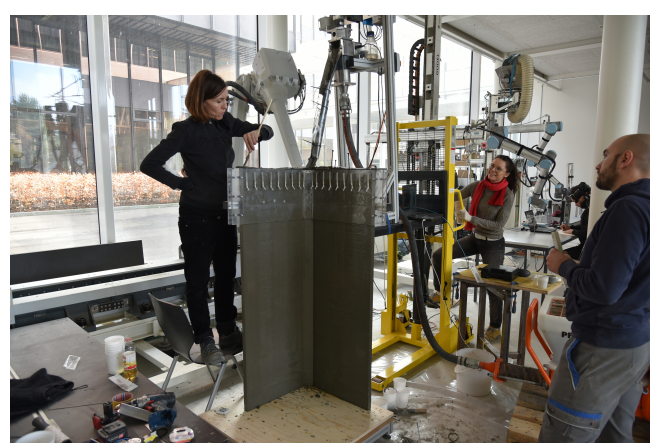

With $8 \mathrm{~mm} / \mathrm{min}$ slipping speed no major cracks formed and no flow out was experienced, thus the process window criterion was fulfilled during the

Figure 6

Robotic slip-casting scheme and the three strands for the geometrical exploration with straight $(A)$, Bezier curved (B) and sine curved trajectories

whole production time. A prototype of $140 \mathrm{~cm}$ height with a relatively smooth surface quality was fabricated with less than 3 hours of slipping (Figure 7). The accelerated concrete was filled into the formwork in the middle with only one channel guiding the accelerated concrete from the mixing reactor, thus continuous manual labour was needed to distribute the concrete along the upper part of the thin folded formwork cross-section.

Curved slipping. Secondly, shaping was tested with a single curved slipping trajectory (see Figure 6) in the vertical symmetry plane of the formwork. The curved folded element was designed with $30 \mathrm{~cm}$ maximum cantilevering at $150 \mathrm{~cm}$ height, thus shaping the concrete in a range of $0-0.35 \mathrm{~cm}$ for every centimetre of height. The first prototype of this geometry was fabricated with $8 \mathrm{~mm} / \mathrm{min}$ slipping speed and although it reached the final height, the last $40 \mathrm{~cm}$ collapsed after slipping it entirely out of the formwork (Figure 8).

However, it can be noticed in Figure 9 that the failure was initiated by buckling approximately $10 \mathrm{~cm}$ below the slipping zone, not directly at the exit of the formwork. The material was in the process window for slipping, its strength was sufficient at the time it exited the formwork. Then, after it was slipped-out
Figure 7

Straight slipping with manual aid for material distribution 
Figure 8

Left: Buckling

highlighted with red circles Right:

Curved prototype after the collapse of its upper part

Figure 9

Curved prototype of the formwork, its strength did not increase rapidly enough to support the cantilevering geometry.

The consecutive experiment with the same geometry resulted in a $121 \mathrm{~cm}$ high prototype with an almost $20 \mathrm{~cm}$ cantilevering and well-defined outline at the upper part of the element (Figure 9).
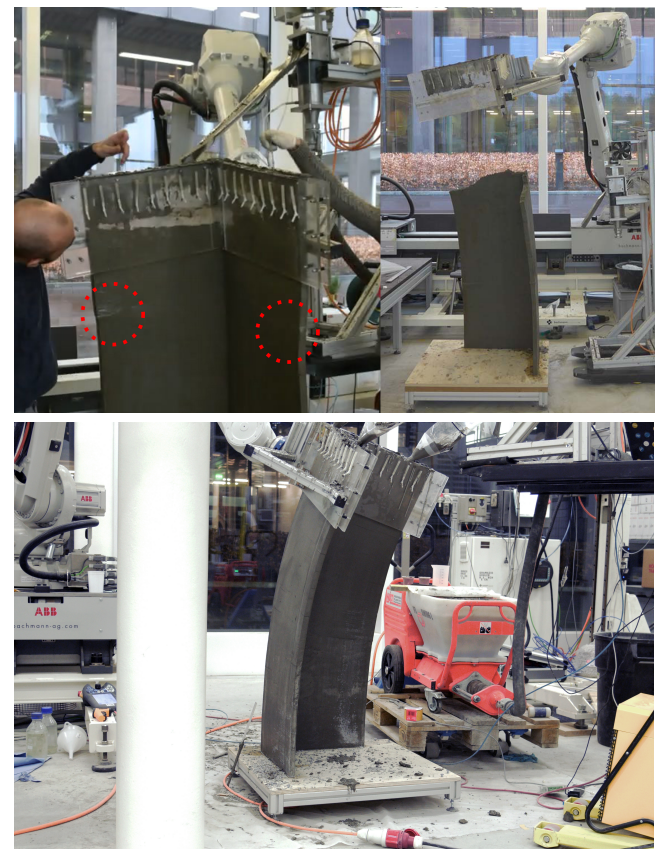

In order to achieve this, the slipping speed was reduced to $6 \mathrm{~mm} / \mathrm{min}$ providing more time for the already slipped parts to gain strength. In addition, it is important to mention that alkaline-resistant glass fibres were integrated into the mix to enhance early tensile strength. Additionally, the accelerated concrete was filled to the formwork with two channels instead of one to allow for better distribution of concrete in the formwork possibly contributing to the success of the experiment with this curved trajectory.

Although the material distribution required less manual labour, it resulted in graded concrete properties where paste and aggregates were not distributed homogeneously during filling. Finally, to prevent the collapse experienced in the previous experiment, the complete slip-out of the prototype was delayed. The formwork was held in the final shaping position for the first few hours of hardening until the element became self-supporting.

Sine curve slipping. Thirdly, sine curve trajectories in the same vertical symmetry plane of the formwork as in the previous experiment were tested (see Figure 6). This geometry aimed to provide more stability for the elements during production. The first design for the sine curved folded element featured $150 \mathrm{~cm}$ height, $8.5 \mathrm{~cm}$ maximum inclination at $60 \mathrm{~cm}$ height achieved with no bigger than $0.23 \mathrm{~cm}$ shaping over $1 \mathrm{~cm}$ height.

The first attempts to fabricate this design ended up in failure despite using the same material composition with fibres and same slipping speed as in the previous successful single curved experiment. The fold line opened up with a crack due to its lateral walls buckling apart (Figure 10). As the failure happened after slip-out, it can be assumed it was due to the too slow material strength evolution again. It is also important to notice that only one channel was available for formwork filling that day, thus the effect of differences in material distribution cannot be neglected.

In order to enhance the fabrication feasibility of this geometry, the shaping degree and total height were left unchanged, while the maximum inclination was reduced to $6.4 \mathrm{~cm}$ occurring at $50 \mathrm{~cm}$ height. With these modifications, a maximum $110 \mathrm{~cm}$ tall prototype (Figure 11) was produced with $6 \mathrm{~mm} / \mathrm{min}$ slipping speed in less than 4 hours of fabrication time. During fabrication, two filling channels were used again to enhance the self-distribution of the concrete within the formwork.

At the end of the experiment, the concept of delayed complete slip-out proved to be beneficial again to prevent buckling. However, the full height was never achieved as early signs suggested that further height increase would have induced the same complete failure mechanism due to buckling as seen before. 

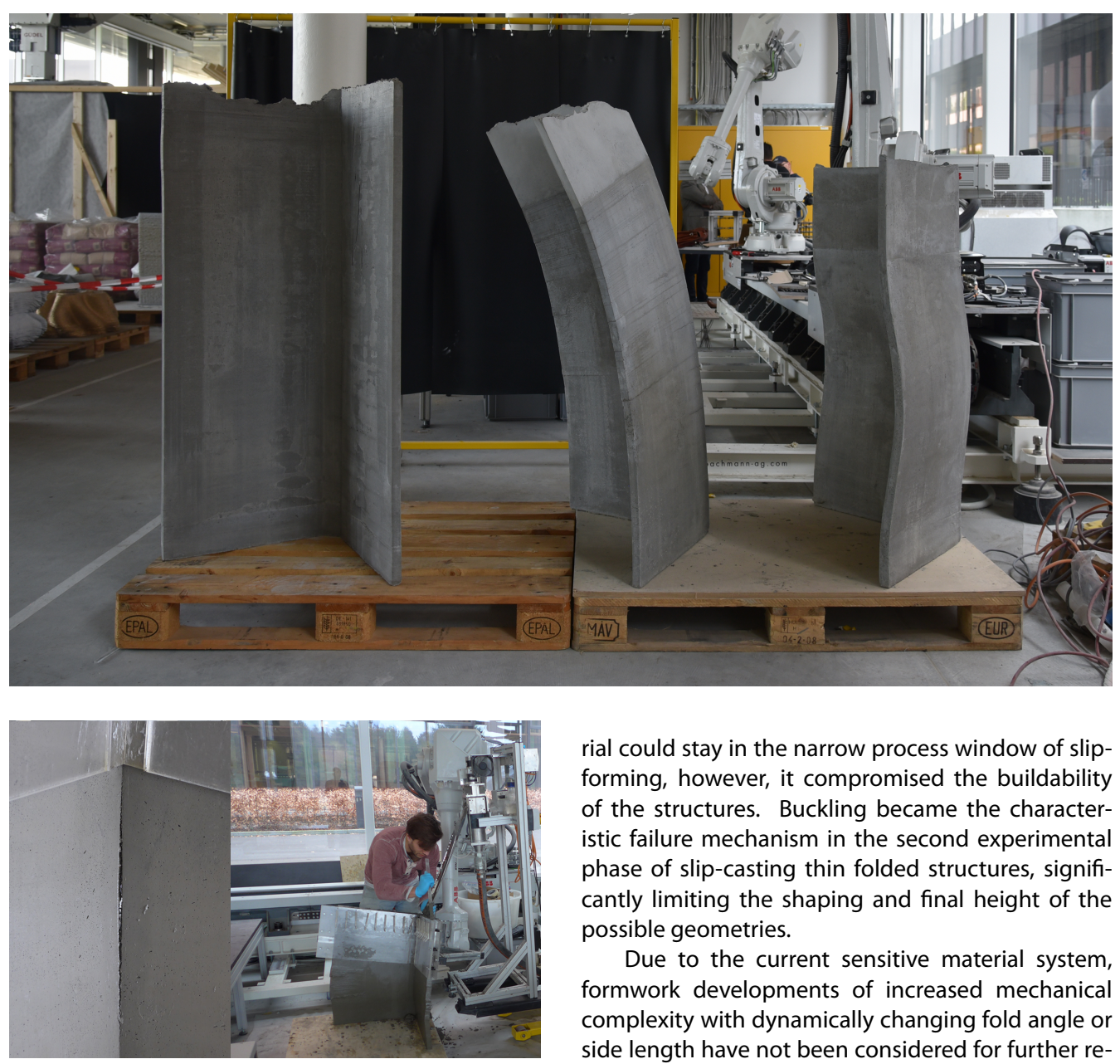

\section{CONCLUSIONS AND OUTLOOK}

The adapted set on demand material with slow strength gain provided a key to successful experiments. It could compensate for the friction acting on the large formwork surface and the material variations at slip-out through the elongated folded cross section. It allowed to extend the time the mate- rial could stay in the narrow process window of slipforming, however, it compromised the buildability of the structures. Buckling became the characteristic failure mechanism in the second experimental phase of slip-casting thin folded structures, significantly limiting the shaping and final height of the possible geometries.

Due to the current sensitive material system, formwork developments of increased mechanical complexity with dynamically changing fold angle or side length have not been considered for further research. This decision is based on the expectation that most probably these changes would have provided additional processing difficulties, thus even smaller design freedom than with the current rigid formwork. Thus, instead of exploring the design space that the actuation of the formwork could provide, the experimental setup was changed to eliminate friction, the main cause of processing difficulties with thin formworks. The moving formwork became detached from
Figure 10

Results of the geometrical exploration with SDC: a straight, a Bezier-curved and a sine curved thin folded prototype

Figure 11

Left: Crack initiated by buckling at the fold line Right: Fabrication before complete collapse 
Figure 12

Sine curve prototype

Figure 13 Left: Digital Casting experiment representing a foil formwork and thin folded geometry Right: Close up to formwork filling with digital casting the robot and remained stationary while the mixing reactor took its place on the robot as an end effector.

The resulting process, Digital Casting (Figure 13) uses a similar set on demand material as SDC and deposits it with a robot arm along a digitally defined path to fill formworks without manual aid for material distribution. It can be beneficial in a collaborative robotic setup for slip-casting thin folded elements providing better control over the material properties when filling concrete along the cross-section. However, it can also function as an individual process with increased design freedom for thin folded elements.
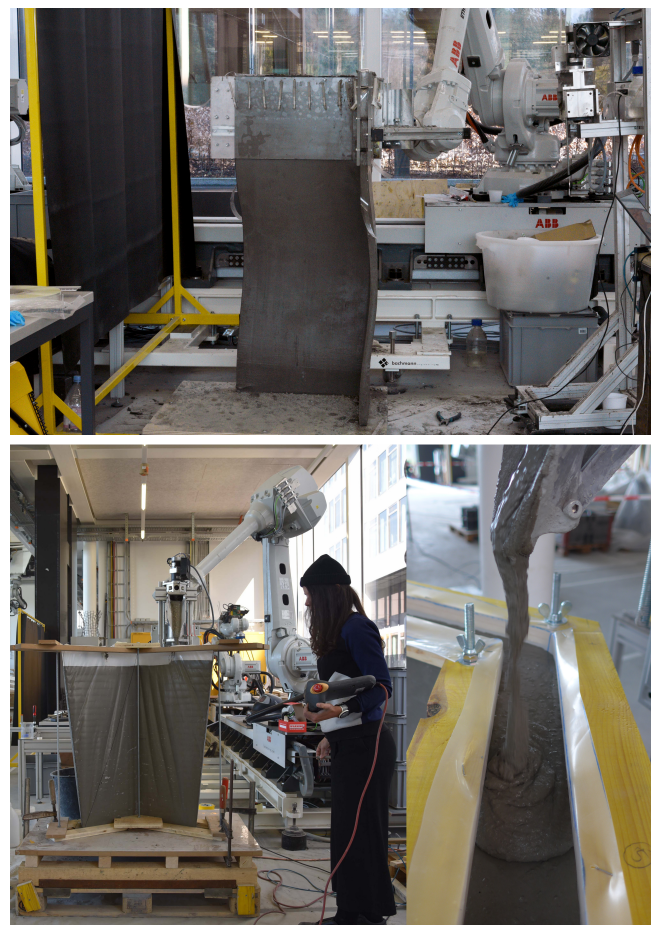

Digital Casting is a less sensitive process where the accelerated concrete has no upper constraint for strength gain, while during slip-casting the material has to stay soft enough until slip-out to prevent cracking due to friction. The risk of buckling is negli- gible compared to slip-casting thanks to the possibility of fast strength evolution and the constant presence of the formwork. The formwork for digital casting can be thin, deformable and weakly supported as the pressure that the concrete exerts on the formwork walls is negligible compared to traditional casting due to the set on demand material system.

During the feasibility study of producing thin folded elements with Digital Casting a new acceleration strategy was developed providing minimal deformation occurring on formworks made of materials with low bending stiffness such as PE foil, PVC sheets, cardboard or different textiles. The first folded prototypes featured changes in thickness and in fold angle, cantilevering sides, integration of posttensioned reinforcement and shear keys. The prototypes inherited the surface texture of the moulds and showed traces of the digital casting process with more or less pronounced layering. However, it is beyond the scope of this paper to discuss these experiments in detail. Nevertheless, Digital Casting has already shown increased potential compared to SDC to become a suitable digital fabrication method for load-bearing mass-customized thin folded structures. Thus, Digital Casting will be further explored to enrich the design language of intricate thin folded shapes produced with set on demand concrete solutions.

\section{ACKNOWLEDGEMENTS}

The research is pursued in the interdisciplinary framework of the National Competence Centre of Research (NCCR) Digital Fabrication funded by the SNSF at ETH Zürich. The authors thank Heinz Richner, Andi Reusser for technical assistance and appreciate the help of Bruno Pinto Aranda, Fabio Scotto, Tom Mundy, Lukas Sigrist, Shaun Wu, Federico Giacomarra, Alan Colmant, Marius Graf and Nicolas Neff during the experiments. The authors are also grateful for the constructive discussions with Prof. Dr. Rafael Pileggi and Dr. Tim Wangler. 


\section{REFERENCES}

Bruno, L, Vacchini, E, Vanetti, M, Laffranchi, M and Kapellos, A 2016, 'Sportausbildungszentrum M"ulimatt in Brugg/ Windisch / M"ulimatt Sports Education and Training Centre in Windisch, Brugg', Best of Detail: Beton/Concrete, 1(1), pp. 620-625

Charleson, A 2005, Structure as architecture : a source book for architects and structural engineers, Routledge, New York (NY)

Chudoba, R, Van Der Woerd, J, Schmerl, M and Hegger, J 2014, 'ORICRETE: Modeling support for design and manufacturing of folded concrete structures', Advances in Engineering Software, 72(August 2014), pp. 119-127

Das, A, Reiter, L, Wangler, T and Flatt, RJ 2019 'Hydration control of ternary cements for digital fabrication with concrete', Submitted to: Proceedings of the 2nd International Conference on Rheology and Processing of Construction Materials, pp. 1-9

Engel, $\mathrm{H}$ and Rapson, R 2007, Tragsysteme - Structure Systems, Hatje Cantz Verlag

Forty, A 2012, Concrete and culture : a material history, Reaktion

Lloret Fritschi, E 2016, Smart Dynamic Casting - A digital fabrication method for non- standard concrete structures, Ph.D. Thesis, ETH Z" urich

Garcia, R 2006, 'Concrete Folded Plates in the Netherlands', Proceedings of the Second International Congress on Construction History, 2, pp. 1189-1208

Hegger, J, Woerd, JDVD, Chudoba, R and Bonfig, C 2017 'Construction of a vault using folded segments made out of textile reinforced concrete by foldin-fresh', Proceedings of the IASS Annual Symposium 2017 "Interfaces: architecture.engineering.science"

Le, TT, Austin, SA, Lim, S, Buswell, RA, Gibb, AG and Thorpe, T 2012, 'Mix design and fresh properties for high-performance printing concrete', Materials and Structures/Materiaux et Constructions, 45(8), pp. 1221-1232

Lloret, E, Shahab, AR, Linus, M, Flatt, RJ, Gramazio, F, Kohler, M and Langenberg, S 2015, 'Complex concrete structures: Merging existing casting techniques with digital fabrication', CAD Computer Aided Design, 60, pp. 40-49

Lynn, G 2013, Folding in Architecture (1993), Wiley

Mettler, LK, Wittel, FK, Flatt, RJ and Herrmann, HJ 2016, 'Evolution of strength and failure of SCC during early hydration', Cement and Concrete Research, 89, pp. 288-296
Nervi, PL 2018, Aesthetics and Technology in Building, University of Illinois Press

Popescu, M, Reiter, L, Liew, A, Van Mele, T, Flatt, RJ and Block, P 2018, 'Building in Concrete with an Ultra-lightweight Knitted Stay-in-place Formwork: Prototype of a Concrete Shell Bridge', Structures, 14(November 2017), pp. 322-332

Reiter, L, Palacios, M, Wangler, T and Flatt, RJ 2015 'Putting Concrete to Sleep and Waking It Up with Chemical Admixtures', Proceedings of the 11th International Conference on Superplasticizers and Other Chemical Admixtures in Concrete, pp. 145-154

Reiter, L, Wangler, T, Roussel, N and Flatt, RJ 2019 'Continuous characterization method for structural buildup', RheoCon2 Conference and SCC9 Symposium

Scotto, F, Lloret-Fritschi, E, Gramazio, F, Kohler, M and Flatt, RJ 2018 'Adaptive Control System for Smart Dynamic Casting', Proceedings of the 23rd International Conference of the Association for Computer-Aided Architectural Design Research in Asia, pp. 255-264.

Szabo, A, Reiter, L, Lloret-fritschi, E, Gramazio, F, Kohler, $M$ and Flatt, RJ 2019 'Processing of set on demand solutions for digital fabrication in architecture', Submitted to: Proceedings of the 2nd International Conference on Rheology and Processing of Construction Materials, pp. 1-8

Szabo, A, Reiter, L, Lloret-Fritschi, E, Gramazio, F, Kohler, $M$ and Flatt, RJ 2018, 'Adapting smart dynamic casting to thin folded geometries', in Wangler, $\mathrm{T}$ and Flatt, RJ (eds) 2018, RILEM Bookseries, Springer International Publishing, pp. 81-93

Wangler, T 2018 'Digital Concrete Processing: A Review', Proceedings of the 1st International Conference on 3D Construction Printing (3DCP 2018)

Wangler, T, Lloret, E, Reiter, L, Hack, N, Gramazio, F, Kohler, M, Bernhard, M, Dillenburger, B, Buchli, J, Roussel, N and Flatt, R 2016, 'Digital Concrete: Opportunities and Challenges', RILEM Technical Letters, 1, p. 67

van der Woerd, JD, Chudoba, R and Hegger, J 2017 'Canopy - Doubly Curved Folded Plate Structure BT - High Tech Concrete: Where Technology and Engineering Meet', Proceedings of the 2017 fib Symposium, Cham, pp. 2512-2520

Wu, S and Giacomarra, F 2017, Computational strategies for design and assembly of thin folded concrete structures, Ph.D. Thesis, ETH Z"urich

[1] http://www.Ifp.rwth-aachen.de/cms/LFP/Forschung /Projekte/\nbra/Concrete-Fold/?lidx=1

[2] https://fib-ch.epfl.ch/Pubs/2018/docs/2区extbacksla sh_buildings.pdf 